\title{
EDUCAÇÃO AMBIENTAL PARA A CONSERVAÇÃO DO RIO SÃO FRANCISCO: DA PERCEPÇÃO A AÇÃO
}

Andrea Luciana de Aragão Ribeiro ${ }^{1}$

Ronise Nascimento de Almeida ${ }^{2}$

Resumo: Esta pesquisa analisa as contribuições das ações educativas e a percepção ambiental da comunidade escolar do campus Penedo - Instituto Federal de Alagoas - IFAL, com foco na conservação do rio São Francisco. Utiliza-se do método da análise do Discurso do Sujeito Coletivo (DSC), com abordagem qualiquantitativa. O resultado da pesquisa aponta a percepção que os alunos entrevistados possuem sobre a importância do rio São Francisco; de como percebem a educação ambiental e as ações educativas promovidas pelo campus Penedo no intento de sensibilizar a comunidade escolar para com conservação do rio, e, por conseguinte, para a promoção de mudança de atitude dos indivíduos que com ele mantém relações de interdependência.

Palavras-chave: Educação; Percepção Ambiental; Rio São Francisco. 


\section{Introdução}

A dependência e ligação existentes entre os ribeirinhos e o rio São Francisco são fatores motivadores para esta pesquisa, uma vez que tal população não sobrevive sem a existência deste curso fluvial. Este elo, também sentimental e cultural, favorece ações de cunho educativo cujos temas envolvam a conservação do rio e promovam o comprometimento das comunidades locais com práticas sustentáveis. Assim, a educação ambiental voltada para a sustentabilidade desse recurso hídrico pode ser uma valiosa aliada no processo de sensibilização das referidas comunidades, sendo também motivação da pesquisa, quando se pretende analisar e comparar como a comunidade escolar percebe a importância do rio e a contribuição que a educação pode dar para a sua revitalização.

Neste contexto, a educação ambiental, considerada por Seifert (2011) alternativa para a eficiência da gestão ambiental e para a materialização do desenvolvimento sustentável, flexibiliza-se como uma educação para ser posta em prática oferecendo alternativas para a formação de sujeitos ecológicos ${ }^{3}$. Conforme Dias (2003, p. 100), a "Educação Ambiental (EA) é um processo por meio do qual as pessoas aprendem como funciona o meio ambiente, como dependemos dele, como o afetamos e promovemos a sua sustentabilidade", viés interdisciplinar da educação que permite ser abordado pelos diferentes conteúdos curriculares.

Portanto, para conservar o meio ambiente faz-se necessário o despertar da consciência ecológica, na qual a educação formal exerce papel fundamental. Neste processo de conscientização ecológica, a forma como as pessoas percebem o meio que as cerca é importante na sua essência para se ter uma visão de como cada indivíduo desenvolve esta percepção ambiental, e como interagem (positiva ou negativamente) com o meio à sua volta.

A função da escola, no cumprimento do seu oficio de formar cidadãos, deve ser implementar ações como: projetos, campanhas, formulação curricular multidisciplinar, entre outros, na perspectiva de promover a educação formal que avance oferecendo alternativas para a formação dos sujeitos (SEIFFERT, 2011), capazes de desenvolver visões alternativas atinentes ao ambiente social na cotidianidade (MARTINS; SOUZA, 2013). A educação para a sustentabilidade desempenha importante papel na mudança de atitude, que poderá será alcançada por meio da utilização sustentável dos recursos naturais, da mitigação dos impactos ambientais e da adoção de ações e práticas educativas ${ }^{4}$ para a promoção de atitudes também sustentáveis,

\footnotetext{
${ }^{3}$ Carvalho (2008) sinaliza que, nos dias atuais, a formação do sujeito deve ultrapassar a prática de transmissão de conteúdo e informação, pois o ensino deve promover subsídios para posicionamentos críticos e reflexivos, em que possibilite a atuação cidadã diante dos problemas ambientais.

${ }^{4}$ Prática docente, prática pedagógica e Prática educativa (Freire, 2013) nesta pesquisa será compreendida de acordo com Freire (2013, p. 142), "como sendo um exercício constante em favor da produção e do desenvolvimento da autonomia de educadores e educandos". Segundo Antunes, ações educativas (2010), são aquelas ações coordenadas para a formação tanto individual e como social dos alunos.
}

Revbea, São Paulo, V. 14, № 2: 09-29, 2019. 
conforme se pretende contribuir com esta pesquisa ao analisar as contribuições das ações educativas e a percepção ambiental da comunidade escolar com foco na conservação do rio São Francisco.

Considerado um dos mais importantes cursos d'água do Brasil e da América Latina, o rio São Francisco foi descoberto em 04 de outubro de 1501, por Américo Vespúcio, era chamado Opará - rio Mar - pelos índios que habitavam suas margens, e recebera este nome em homenagem ao dia de São Francisco de Assis. É também conhecido por "Velho Chico" e "rio da integração nacional" por ter sua bacia ocupando unicamente o território nacional brasileiro conforme afirmam a Companhia de Saneamento de Sergipe (DESO) e o Comitê da Bacia Hidrográfica do São Francisco (CBHSF) (2016).

A Bacia Hidrográfica ${ }^{5}$ do São Francisco (BHSF) é a terceira maior do país, sendo uma das doze regiões hidrográficas do Brasil, e tem grande importância nacional não apenas pelo volume de água transportado em uma região semiárida, mas também pelo potencial hídrico passível de aproveitamento e por sua contribuição histórica e econômica para a região, conforme afirma o CBHSF e a Companhia Energética de Minas Gerais (CEMIG) (2016).

O surgimento e desenvolvimento socioeconômico de grande parte das cidades que margeiam o rio São Francisco deram-se pela existência deste recurso hídrico. O progresso oriundo da exploração do rio possibilitou o crescimento das cidades ribeirinhas ${ }^{6}$ em todos os aspectos, por consequência, não permitindo que a regeneração deste recurso natural ocorresse, promovendo a sua degradação (AGUIAR NETTO et al., 2011, 2015; FONTES, 2011). Assim, faz-se necessária a adoção de ações que devolvam ao rio a condição de manter-se para as gerações futuras e possam mitigar os impactos ambientais $^{7}$ já evidenciados.

Promover sua conservação ${ }^{8}$ é também garantir os serviços que o rio São Francisco tem prestado às comunidades ribeirinhas e para outras grandes cidades que, embora não se situam nas suas margens, são também por ele atendidas mediante a utilização de suas águas. Dentre estes serviços estão o fomento à agricultura, a fruticultura, e a pecuária; a exploração energética por meio das nove usinas hidrelétricas instaladas em toda a extensão do rio, com capacidade de geração de 9.973,50 MW ${ }^{9}$, fornecendo energia para a Região Nordeste e algumas regiões do Sudeste brasileiro, bem como o abastecimento de água para o consumo da população urbana, rural e das indústrias

\footnotetext{
${ }^{5}$ Segundo a Agência Nacional de Águas - ANA (2011), bacia hidrográfica é a região compreendida por um território e por diversos cursos d'água.

${ }^{6}$ Para Matos (2014, p. 59), cidades localizadas às margens dos rios e dependem de seus recursos naturais.

${ }^{7}$ Seiffert (2011, p. 19) conceitua que é a alteração da qualidade do meio gerada por qualquer forma de energia e/ou matéria produzida pela atividade humana.

${ }^{8}$ De acordo com Seiffert (2011), entende-se por conservação ambiental como a exploração racional dos recursos naturais de modo a garantir sua sustentabilidade.

${ }^{9} \mathrm{Cfe}$. Relatório de Demonstrações Financeiras da Companhia Hidro Elétrica do São Francisco - CHESF, 2015.
} 
localizadas em seu entorno, chegando a beneficiar cerca de 16 milhões de pessoas (CEMIG, 2016; ANA, 2011).

O Baixo São Francisco (BSF), que se inicia na cidade de Paulo Afonso (BA) e termina na foz no Oceano Atlântico, reproduz a mesma realidade das demais regiões do rio, no que diz respeito à dependência das comunidades, e assim como em toda a sua extensão, o Velho Chico mantém-se como importante recurso provedor do desenvolvimento e subsistência, além de conviver com os impactos causados por fatores naturais e pela ação antrópica ${ }^{10}$. Tais fatores podem ser evidenciados no desmatamento da vegetação ciliar, causando assoreamento e erosão; barramento do curso natural do rio para exploração energética, causando a redução da vazão, trazendo entraves para a navegação pelo surgimento de bancos de areia no leito do rio e impedindo a reprodução de peixes reofílicos ${ }^{11}$; transposição de suas águas; desaparecimento de afluentes importantes, seca por baixo índice pluviométrico, causando restrição hídrica; uso da água para irrigação; descarte de resíduos sólidos e despejo de esgotos domiciliares e industriais sem tratamento, dentre outros.

A combinação destes fatores está intimamente relacionada à ausência de fiscalização e planejamento urbano (ordenamento territorial), promovendo perdas ao meio ambiente ${ }^{12} \mathrm{e}$, consequentemente, restringindo a qualidade de vida da comunidade local (VIEIRA et al., 2002), exigindo uma maior reflexão em torno da necessidade de mudanças urgentes na relação que as populações e governo mantêm com o rio.

Neste contexto, o Instituto Federal de Educação, Ciência e Tecnologia (IF), conforme determina a Lei 11.892 de 2008, de sua criação, e outros documentos institucionais, volta-se para "ofertar educação profissional e tecnológica, em todos os seus níveis e modalidades, formando e qualificando cidadãos com vistas à atuação profissional nos diversos setores da economia, com ênfase no desenvolvimento socioeconômico local, regional e nacional" (BRASIL, 2008), também se preocupa com as questões voltadas para a sustentabilidade, segundo explicita em seu artigo $6^{\circ}$, item IX, que determina "promover a produção, o desenvolvimento e a transferência de tecnologias sociais, notadamente as voltadas à preservação do meio ambiente" (BRASIL, 2008).

No Plano de Desenvolvimento institucional (PDI) (IFAL 2014, p. 40 e 41), o IFAL possui dentro de seu diagnóstico estratégico, como direcionadores, a

\footnotetext{
${ }^{10}$ São as alterações do homem sobre o meio ambiente (SEIFFERT, 2011).

${ }^{11}$ São aqueles que precisam realizar a migração reprodutiva, nadando contra a correnteza das águas para favorecer o amadurecimento de suas gônadas e se reproduzir. O barramento causado pelas hidrelétricas impede a reprodução destas espécies que precisam percorrer longas distâncias para amadurecimento de suas gônadas (MACHADO JUNIOR, 2010).

${ }^{12}$ Meio ambiente é o conjunto dos elementos abióticos (físicos e químicos) e bióticos (fauna e flora), organizados em diferentes ecossistemas naturais e sociais em que se insere o homem, individual e socialmente, num processo de interação que atenda ao desenvolvimento das atividades humanas, à preservação dos recursos naturais e das características essenciais do entorno, dentro das leis da natureza e de padrões de qualidade definidos (COIMBRA, 2002, p. 33).
}

Revbea, São Paulo, V. 14, № 2: 09-29, 2019. 
missão de "contribuir para o desenvolvimento sustentável", tendo como um de seus valores o compromisso com a sustentabilidade por meio da instituição e disseminação de práticas de cunho sustentável. Assim, percebe-se a importância de se desenvolver uma educação interdisciplinar pautada nestes valores e práticas que visam o desenvolvimento socioeconômico local, bem como a conservação dos recursos naturais.

\section{Metodologia}

Este estudo foi realizado no campus Penedo do Instituto Federal de Educação, Ciência e Tecnologia de Alagoas (IFAL), município situado na margem alagoana da região do rio São Francisco, denominada como Baixo São Francisco, que possui seu processo de desenvolvimento histórico, econômico e social ligado ao rio e convive intrinsecamente com os problemas oriundos da degradação ambiental evidenciada pelo rio.

Para responder as questões levantadas e atingir os objetivos propostos, esta pesquisa realizou-se em três etapas, de forma exploratória e descritiva, a partir de uma abordagem quantitativa, no intento de analisar a percepção que os discentes dos cursos técnicos integrados em Meio Ambiente e Açúcar e Álcool têm a respeito da importância do rio São Francisco para a comunidade da cidade de Penedo ( $\mathrm{AL}$ ); da sua evidente degradação e do papel que a educação ambiental pode desempenhar para a conservação deste recurso natural.

A fase exploratória é aquela em que o pesquisador explora o campo de pesquisa no intento de apontar problemas e os agentes envolvidos. Thiollent (1986, p. 48) explica que "a fase exploratória consiste em descobrir o campo de pesquisa, os interessados e suas expectativas e estabelecer um primeiro levantamento (ou "diagnóstico") da situação, dos problemas prioritários e de eventuais ações". Já para Gil (2012, p. 28), "as pesquisas descritivas têm como objetivo primordial descrição das características de determinada população ou fenômeno ou, então, o estabelecimento de relações entre variáveis".

$\mathrm{O}$ estudo foi conduzido pelas pesquisas bibliográfica, documental e de campo, utilizando o método do Estudo Comparativo de Casos, que, segundo Triviños (2013, p. 136), permite "estabelecer comparações entre dois ou mais enfoques específicos",

Para Abílio e Sato (2012, p. 23), a pesquisa quantitativa, por sua vez, "trabalha a partir do momento em que o objeto investigado é assumido pelo investigador como contável/mensurável".

Para a composição da amostra, foram selecionados alunos do $4^{\circ}$ ano dos cursos presenciais técnicos integrados, por estarem no último ano letivo e terem, durante o período de formação no IFAL, se envolvido em ações educativas ou projetos de pesquisa e extensão que tiveram a conservação do rio São Francisco como foco. Estes discentes estavam devidamente matriculados no corrente ano letivo e com frequência global superior ou igual a $75 \%$. 
Esta amostra foi composta por 59 alunos, dos quais 26 alunos pertenciam ao curso de Meio Ambiente e 33 cursavam o curso de Açúcar e Álcool. Destes, 20 homens e 39 mulheres, selecionados aleatoriamente. Da amostra selecionada, 22 indivíduos residem na cidade de Penedo, enquanto 4 moram em cidades circunvizinhas. Todos assinaram o termo de consentimento de livre esclarecimento e tiveram suas identidades preservadas, estando cientes das questões as quais foram submetidos, bem como da finalidade deste estudo. Cada grupo de entrevistados recebeu um código, de forma a permitir a distinção e discrição na análise dos dados.

$\mathrm{Na}$ primeira etapa da pesquisa foram coletados os dados secundários por meio da revisão bibliográfica em recursos como livros, artigos, trabalhos acadêmicos e internet acerca do tema foco desta pesquisa, no intento de levantar informações sobre os principais fatores que impactam o Rio São Francisco na atualidade e indicadores sociais que caracterizam impactos ambientais no Baixo São Francisco, bem como a respeito da importância da análise da percepção ambiental para a condução do processo de educação das comunidades ribeirinhas que compõem a comunidade escolar em análise nesta pesquisa.

Ainda nesta etapa, foi realizada a pesquisa documental por meio da análise dos documentos do campus que evidenciam a ocorrência de ações educativas que envolvam a conservação do rio São Francisco como temática. Inicialmente, foram levantados todos os documentos, desde a fundação do campus Penedo, no ano de 2010, até o ano de 2017. Foram contemplados nesta análise relatórios de ocorrência de atividades promovidas, como campanhas, feiras, seminários, eventos científicos, além dos relatórios de projetos de pesquisa e extensão.

Inicialmente cada projeto executado foi analisado, e em seguida, foram selecionados os documentos referentes às ações que possuem o rio São Francisco como tema através da análise dos títulos e objetivos gerais. Destes, foram extraídos os documentos que trazem como proposta a conservação do rio para a análise documental.

A análise destes documentos objetivou quantificar e descrever as ações educativas desenvolvidas podem contribuir de forma a sensibilizar estas comunidades para serem agentes atuantes na conservação do rio São Francisco, bem como traçar um comparativo de como cada curso se sensibiliza com estas ações.

A segunda etapa explorou as pesquisas de campo, levantando os dados primários da pesquisa. Para Minayo (2012, p. 64), "a entrevista tem por objetivo construir informações pertinentes para um objeto de pesquisa, e abordagem pelo entrevistador, de temas igualmente pertinentes com vistas a este objetivo". Esta etapa caracterizou-se pela coleta dos dados primários por meio da aplicação de técnicas de entrevistas estruturadas, com questões fechadas. A direção do campus teve ciência da ocorrência da pesquisa, emitindo parecer favorável à sua realização. As entrevistas ocorreram em dias alternados, em 
datas e horários definidos pelos discentes de acordo com suas disponibilidades e realizadas individualmente por um único entrevistador. As entrevistas foram registradas por meio de formulário escrito, de modo que a pergunta era feita ao entrevistado e este registrava a sua opinião a respeito do questionamento feito. Foi garantido ao participante o seu anonimato.

A última etapa consistiu na análise e interpretação dos dados coletados nas entrevistas, que foram tabulados e organizados através do software DSCsoft, elaborado para o desenvolvimento de pesquisas qualiquantitativas que utilizam o método do Discurso do Sujeito Coletivo (DSC) (LEFRĖVRE, 2010), pela Tolteca Soluções em Informática, que reuniu as opiniões registradas na pesquisa, gerando os dados quantitativos apresentados.

\section{Resultados e Discussões}

O questionário utilizado na pesquisa tinha 4 questões de múltipla escolha em que os entrevistados registravam sua opinião.

Inicialmente, é preciso considerar como a comunidade entrevistada percebe o rio São Francisco, sua importância e, consequentemente, sua problemática. Tal análise permite entender a ligação existente entre os indivíduos pesquisados e o Velho Chico, e como eles podem ou não considerar a educação ambiental como ferramenta importante, contribuinte para a sua sustentabilidade.

Assim sendo, a comunidade escolar foi questionada incialmente a respeito da importância do rio São Francisco para a cidade. A questão possuía quatro opções de escolha, podendo-se observar três delas na Figura 1 a seguir. A quarta opção expunha que o rio não é importante para a comunidade local.

Dentre as respostas analisadas, observa-se que embora o rio seja apontado como importante recurso natural local, promotor do desenvolvimento regional, contribuindo para o crescimento econômico da cidade onde se localizam os indivíduos estudados (Categoria A), alguns entrevistados destacam ainda sua importância ecológica, uma vez que é berço para diversidade de espécies aquáticas que sobrevivem e dependem da qualidade de suas águas (categoria $\mathrm{C}$ ). Para os demais, o rio é visto como importante recurso natural, dentre os demais da cidade (Categoria B), contribuindo também para o desenvolvimento local (Figura 1). 


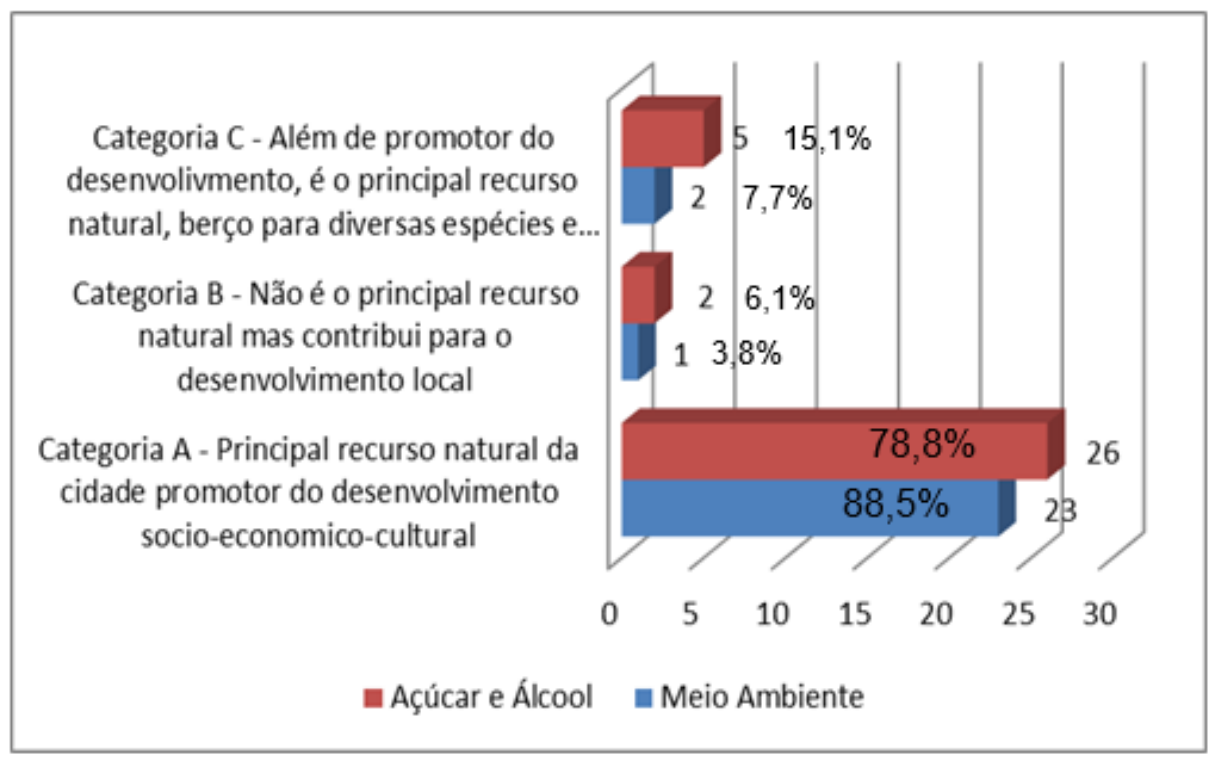

Figura 1: Gráfico comparativo da percepção ambiental da comunidade escolar a respeito da importância do rio São Francisco.

Fonte: Elaborado a partir de dados obtidos nesta pesquisa, 2017.

De um modo geral, a importância do rio São Francisco é vista por $84,0 \%$ dos entrevistados pelo viés histórico, social e econômico, enquanto $12,3 \%$ compreendem a sua importância como habitat de seres vivos e fonte de vida. Apenas 3,7\% percebem o rio como importante recurso natural, mas não o principal recurso natural local.

Avaliando os dados encontrados, observa-se que o percentual dos indivíduos do curso de Açúcar e Álcool que percebem a importância ecológica do rio é maior que o do curso de Meio Ambiente. Embora tenham uma formação voltada para a produtividade industrial, os docentes do curso de Açúcar e Álcool evidenciam que conseguem distinguir no rio São Francisco, além da sua capacidade de promotor do desenvolvimento local, o seu papel de veículo de vida para as comunidades que dele dependem.

Os dados coletados na pesquisa demonstram em percentual que embora tenham sua formação em áreas distintas, os indivíduos percebem a importância do rio São Francisco e sua contribuição para a formação das comunidades em torno de suas margens, e que dele foi possível alavancar o crescimento econômico. A cidade de Penedo (AL) depende da manutenção da conservação deste recurso natural para que continue seu processo de desenvolvimento.

Da mesma forma como reconhecem a importância do rio, a comunidade declara preocupação com a sua evidente degradação, como baixa na vazão natural, redução das populações aquáticas, surgimento de bioindicadores que evidenciam a presença de poluentes, dentre outros. Assim, foi questionada a respeito de quais agentes seriam promotores e/ou contribuintes para este problema. Para tal, foram 10 alternativas, onde o entrevistado destacava 0 
agente que, na sua opinião, mais contribuía para este estado de degradação que o rio apresenta.

Porém, dentre os agentes que contribuem no processo de degradação do São Francisco escolhidos pelos entrevistados estão: a falta de políticas públicas voltadas para a conservação do rio, bem como a pouca fiscalização por parte das autoridades competentes para que se faça cumprir o que determina a legislação vigente (23,0\%); a ausência de saneamento básico observada em algumas localidades destas cidades e o lançamento de esgoto e outros efluentes sem tratamento no rio $(18,0 \%)$; desmatamento da vegetação ciliar $(16,0 \%)$, causando o assoreamento, processo erosivo que promove o aporte dos sedimentos para o leito dos cursos d'água (HOLANDA, et al. 2010), conforme visualizado na Figura 2 a seguir:

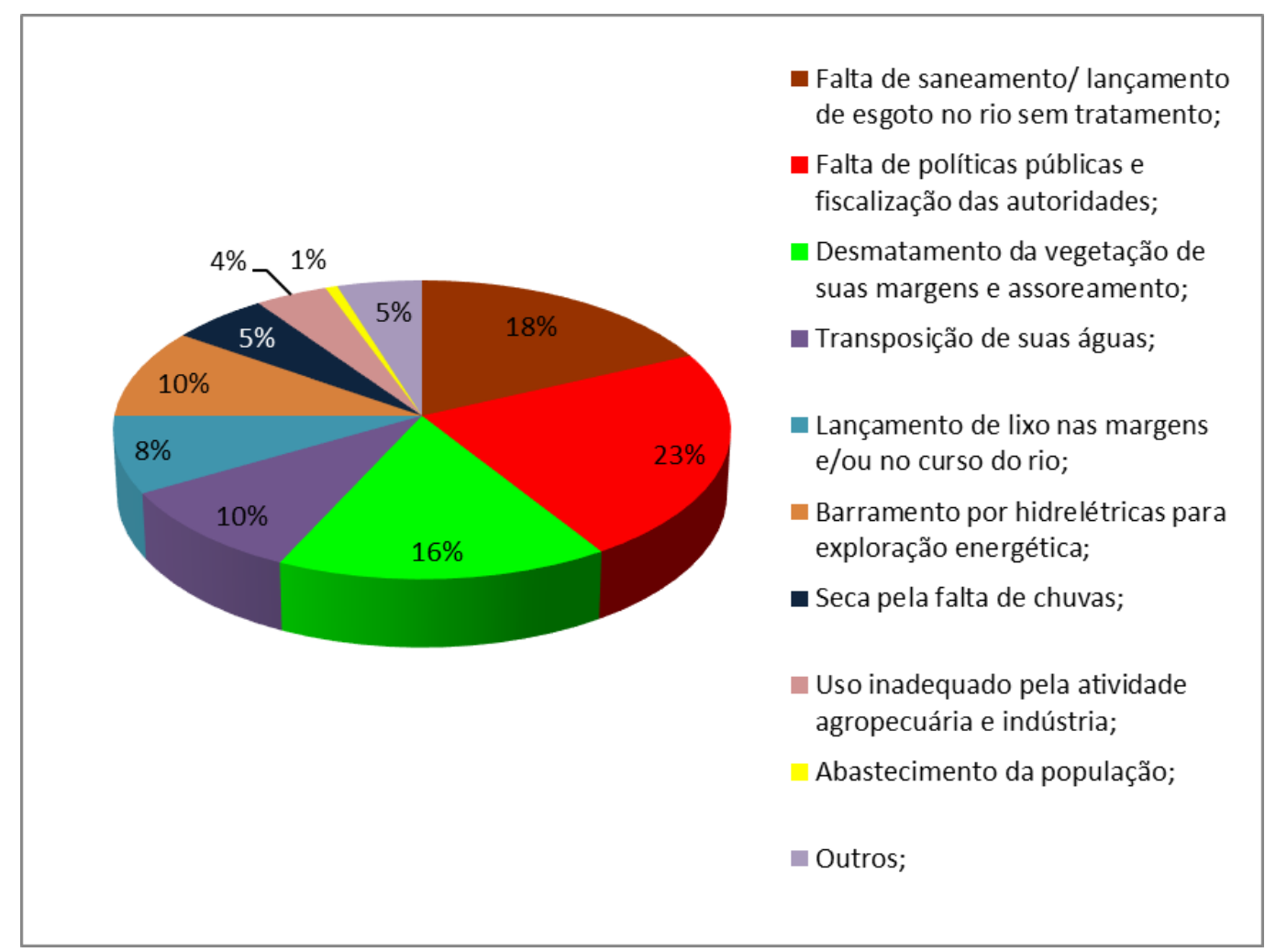

Figura 2: Gráfico comparativo da percepção da comunidade escolar a respeito dos agentes que degradam o rio São Francisco.

Fonte: Elaborado a partir de dados obtidos nesta pesquisa, 2017.

A redução da vazão do rio é evidente e vem sendo difundida pelos meios de comunicação, instituições (ANA, 2016; CBHSF, 2016; CHESF, 2017) e por autores (CHAGAS, 2009; FONTES, 2011; MATOS, 2014). A comunidade entrevistada percebe também esta evidência atribuindo tal fato ao processo natural causado pelo baixo índice pluviométrico, bem como ao processo de transposição e ao barramento de suas águas pelo complexo hidrelétrico para a produção de energia elétrica, conforme apresentado na Figura 2 anterior.

Revbea, São Paulo, V. 14, № 2: 09-29, 2019. 


\section{a) Percepção ambiental da comunidade escolar a respeito da educação e sua contribuição para a sustentabilidade do rio São Francisco}

Estando o IFAL instalado em duas cidades ribeirinhas (Penedo e Piranhas), como instituição de fomento a educação para formação de cidadãos conscientes de seu papel para com o meio em que vivem, surgiu o questionamento sobre como a comunidade escolar entrevistada percebe o papel da educação e como também ela pode atuar em prol da conservação do rio.

Dentre os 59 entrevistados, todos percebem a educação da população como importante aliado no processo de conservação do rio São Francisco, reconhecendo a importância de se promover a conscientização e/ou sensibilização da comunidade por meio de ações educativas, já reconhecido por meio desta pesquisa, como importante recurso natural e promotor do desenvolvimento socioeconômico destas regiões ribeirinhas.

\section{b) Educação em ação - o IFAL em prol do "Velho Chico"}

No intento de atender aos direcionadores estratégicos definidos em seu PDI, o IFAL tem sua missão fundamentada nos princípios da indissociabilidade entre o ensino, a pesquisa e a extensão, contribuindo para o desenvolvimento sustentável e com a formação de indivíduos críticos, capazes de desenvolver sua cidadania em consonância com a sociedade (PDI, 2014-2018).

Neste contexto, além do cumprimento curricular e da formação profissional desenvolvidos pelo ensino, o IFAL atende à sociedade na construção do conhecimento, incentivando e apoiando "as atividades de pesquisa e de inovação, a fim de suscitar o desenvolvimento de soluções técnicas e tecnológicas que contribuam para o enfrentamento dos problemas que afetam a nossa sociedade" (IFAL/PDI, 2014-2018, p. 94); e na difusão deste conhecimento construído com a comunidade, buscando atender as suas necessidades, "em todos os domínios sociais para os quais tenha potencial de atuação, nos âmbitos tecnológicos, cultural, político e educacional" (IFAL/PDI, 2014-2018, p. 113) por meio das atividades de extensão.

Para apontar os resultados das iniciativas do campus Penedo para com a conservação do rio São Francisco, esta pesquisa deteve-se na análise dos projetos de pesquisa e extensão que a instituição executou desde o período de sua instalação até o ano de 2017, bem como das campanhas, semanas tecnológicas e eventos afins que tivessem como temática a conservação do rio São Francisco.

\section{Análise dos projetos de extensão}

Observemos na Figura 3 a seguir, a quantidade de projetos de extensão desenvolvidos no período contemplado por esta pesquisa, bem como a avaliação dos projetos que possuíam na sua temática a conservação do rio São Francisco, buscando difundir na comunidade informações construtivas para a sustentabilidade deste recurso natural. 


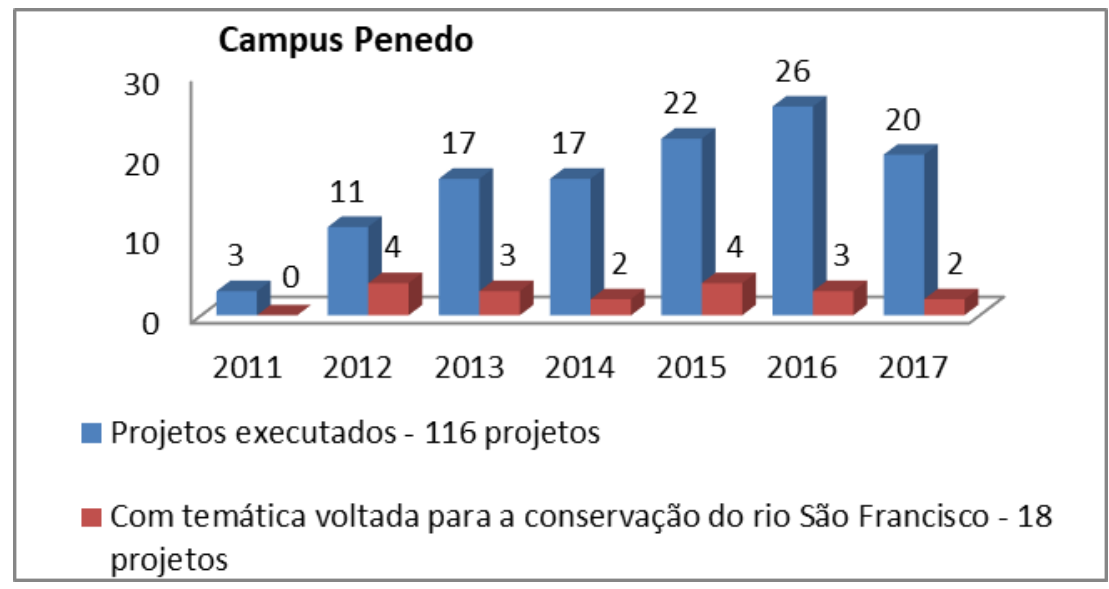

Figura 3: Projetos de extensão do campus Penedo, no período de 2010 a 2017.

Fonte: Elaborado para esta pesquisa, 2017.

Assim, dos 116 projetos executados pelo campus Penedo, 17 possuíam as suas ações voltadas para a conservação do rio São Francisco, perfazendo $14,6 \%$ dos projetos executados.

A Tabela 1 a seguir apresenta os projetos, em seus respectivos períodos, executados por cada campus, que possuíam temática voltada para a conservação do rio.

Tabela 1: Descrição dos projetos de extensão desenvolvidos pelo campus Penedo com foco na conservação do rio São Francisco.

\begin{tabular}{|c|c|}
\hline $\begin{array}{l}\text { Ano de } \\
\text { execução }\end{array}$ & Penedo \\
\hline \multirow{3}{*}{2012} & Água - "Fonte de vida". \\
\hline & Práticas sustentáveis a partir do óleo de cozinha. \\
\hline & Visando o Futuro. \\
\hline \multirow{3}{*}{2013} & Impactos socioambientais causados pelas indústrias sucroalcooleiras. \\
\hline & $\begin{array}{l}\text { Toxicidade dos metais pesados: Descarte adequado para pilhas e baterias na } \\
\text { comunidade de Penedo. }\end{array}$ \\
\hline & Práticas sustentáveis a partir do óleo de cozinha. \\
\hline \multirow{2}{*}{2014} & Caminhos do São Francisco \\
\hline & Sensibilização ambiental da comunidade \\
\hline \multirow{4}{*}{2015} & $\begin{array}{c}\text { Penedo mais verde: Recuperação da mata ciliar da bacia do rio São Francisco } \\
\text { através da educação ambiental em escolas públicas. }\end{array}$ \\
\hline & Práticas sustentáveis a partir do óleo de cozinha. \\
\hline & Rio São Francisco - um patrimônio a zelar. \\
\hline & Pesca consciente - Zona 2 \\
\hline \multirow{3}{*}{2016} & Educação ambiental para formação de cidadãos ecológicos. \\
\hline & Penedo mais verde - adote uma árvore! \\
\hline & Sabão ecológico a base de óleos residuais de frituras. \\
\hline \multirow{2}{*}{2017} & Sabão ecológico a base de óleos residuais de frituras. \\
\hline & Rio São Francisco - um patrimônio a zelar. \\
\hline
\end{tabular}

Fonte: Elaborado para esta pesquisa, 2017.

Revbea, São Paulo, V. 14, № 2: 09-29, 2019. 
Analisando-se qualitativamente, embora abordem a temática comum da conservação do rio São Francisco nas suas ações, alguns destes projetos possuem distinções. Dentre as similaridades mais presentes está a conscientização da população a respeito dos impactos ambientais sofridos pelo rio, seja pelo lançamento de efluentes, seja pelo lançamento de lixo em suas margens e nas ruas das cidades, ou ainda pelo desmatamento da vegetação ciliar etc.; e da necessidade da efetiva promoção de sua conservação.

Podem-se apontar as ações dos projetos: "Práticas sustentáveis a partir do óleo de cozinha" e "Sabão ecológico a base de óleos residuais de frituras", cujo foco principal foi orientar a comunidade envolvida a descartar corretamente o óleo utilizado no preparo de alguns alimentos, bem como dos impactos ambientais que este descarte incorreto pode acarretar, inclusive nos recursos hídricos. Ademais, houve ainda o objetivo de mostrar a reutilização deste produto para a confecção de sabão caseiro, sendo uma possível fonte de renda, uma vez que algumas comunidades circunvizinhas do campus possuem pessoas com rendimento insuficiente ou muito baixo.

Já os projetos "Água - Fonte de vida", "Educação ambiental para a formação de cidadãos ecológicos", "Sensibilização ambiental da comunidade", propunham conscientizar a população das comunidades circunvizinhas aos campi a respeito da importância do rio São Francisco, da conservação da água, dos impactos ambientais evidenciados e de alternativas viáveis para o uso sustentável destas águas.

Os projetos "Rio São Francisco - um patrimônio a zelar", "Visando o futuro" e "Caminhos do São Francisco", foram voltados para a conscientização da população a respeito da poluição urbana e das margens do rio, que podem sofrer lixiviação pelas chuvas e, com isso, levar ao acúmulo de resíduos no rio. Outras ações destes projetos consistiram em atividades de coleta de resíduos nas margens do São Francisco, propondo a reciclagem do material encontrado, e consequentemente a manutenção da qualidade das águas.

Os projetos "Penedo mais verde: Recuperação da mata ciliar da bacia do rio São Francisco através da educação ambiental em escolas públicas" (Ver figura 09 A), "Penedo mais verde - adote uma árvore" propõem a conscientização da comunidade a respeito da preservação das espécies nativas e da mata ciliar do rio.

Alguns destes projetos, porém, possuem objetivos bem específicos, como o projeto "Pesca consciente - zona 2", que objetivou conscientizar os pescadores locais a respeito das boas práticas ambientais com relação ao descarte e destinação dos resíduos por eles gerados no processamento do pescado após captura, no intento de também transformá-los em agentes multiplicadores de saberes e práticas.

O projeto "Toxicidade dos metais pesados: Descarte adequado para pilhas e baterias na comunidade de Penedo", teve como proposta conscientizar a população a respeito do descarte adequado e coleta de pilhas e baterias, uma vez que tais elementos podem comprometer seriamente o solo e lençóis Revbea, São Paulo, V. 14, № 2: 09-29, 2019. 
freáticos, levando os metais pesados neles encontrados, para as águas do rio São Francisco.

Por fim, o projeto "Impactos socioambientais causados pelas indústrias sucroalcooleiras", como o próprio título sugeriu, abordou os impactos socioambientais causados pela produção e processamento da cana-de-açúcar, muito presente na região de Penedo. Com relação ao rio São Francisco, as ações contemplaram o uso de agrotóxicos no processo produtivo, uma vez que resíduos de seu uso podem ser lixiviados para o rio por meio da irrigação e das chuvas.

\section{Análise dos projetos de pesquisa}

A pesquisa do IFAL também realizou sua contribuição na construção do conhecimento e no fomento a formação de indivíduos capazes de buscar soluções para os problemas do cotidiano. Observemos os dados quantitativos da pesquisa realizada pela Instituição no período contemplado por esta pesquisa (Figura 4):

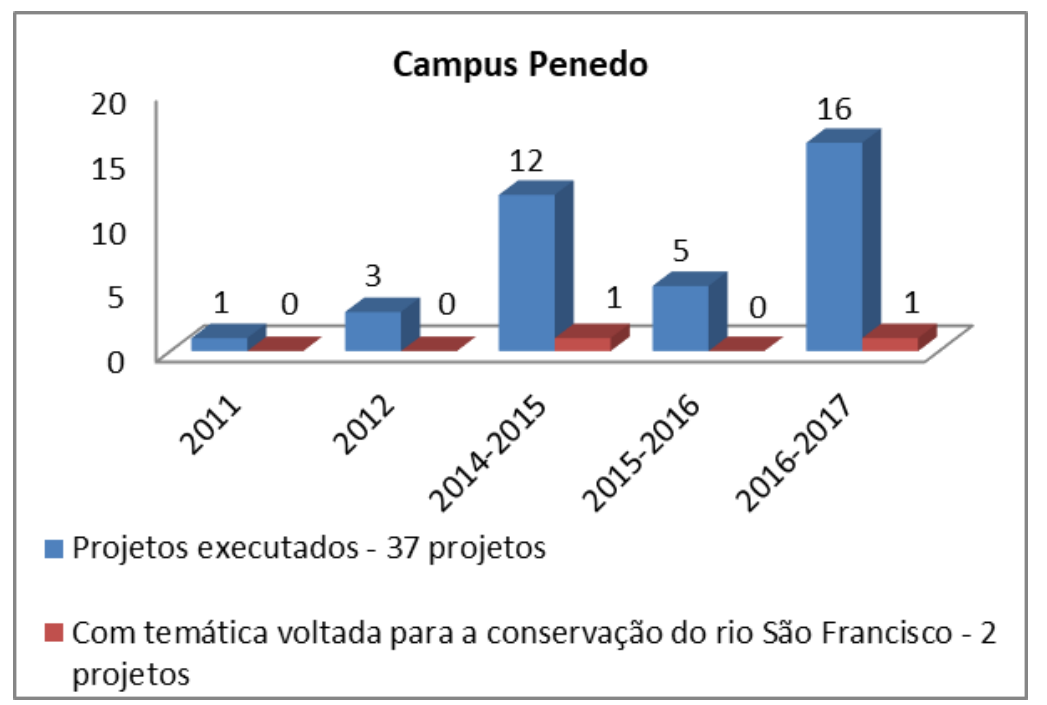

Figura 4: Projetos de pesquisa do campus Penedo, no período de 2010 a 2017.

Fonte: Elaborado para esta pesquisa, 2017.

Não foi possível registrar os dados relacionados aos projetos pesquisa no ano de 2013, pois pelos documentos disponibilizados pela pró-reitoria de pesquisa, não se pôde distinguir projetos pertencentes ao campus estudado nesta pesquisa. Também não foi localizado nenhum projeto de pesquisa na documentação da coordenação de pesquisa do campus que evidenciasse pesquisas neste período.

Assim, dentre os 37 projetos de pesquisa executados pelo campus Penedo desde o ano de 2010 até o ano de 2017, 2 deles contemplavam em 
algum de seus objetivos a conservação do rio, totalizando um percentual de $5,4 \%$ dos projetos executados.

A Tabela comparativa 2, apresentada a seguir, demonstra os projetos de pesquisa executados voltados para a sustentabilidade do rio São Francisco no período contemplado por esta pesquisa.

Tabela 2: Descrição dos projetos de pesquisa desenvolvidos pelos campi Penedo e Piranhas, com foco na conservação do rio São Francisco.

\begin{tabular}{|c|c|}
\hline $\begin{array}{c}\text { Ano de } \\
\text { execução }\end{array}$ & Penedo \\
\hline $2014 / 2015$ & $\begin{array}{c}\text { Mapeamento do estado ambiental da região do Baixo São Francisco } \\
\text { através de Sistema de Informação Geográfica - SIG. }\end{array}$ \\
\hline $2016 / 2017$ & $\begin{array}{c}\text { Estudo do tratamento da vinhaça através de processo oxidativo } \\
\text { avançado - PIBIC. }\end{array}$ \\
\hline
\end{tabular}

Fonte: Elaborado para esta pesquisa, 2017.

Analisando qualitativamente, os projetos de pesquisa desenvolvidos pelo campus em estudo, embora objetivem em algum momento a construção do conhecimento voltado para a conservação do rio São Francisco não possuem similaridades, uma vez que cada projeto tem suas diferentes formas de contribuir para o alcance da sustentabilidade do rio.

O projeto PIBIC "Estudo do tratamento da vinhaça através de processo oxidativo avançado", do campus Penedo, objetivou analisar alternativas para propor o tratamento da vinhaça, efluente gerado no processo de etanol, rico em compostos orgânicos e recalcitrantes, com alto poder contaminante para 0 lençol freático.

O projeto PIBIC do campus Penedo "Mapeamento do estado ambiental da região do Baixo São Francisco através de Sistema de Informação Geográfica - SIG" propôs-se a realizar um mapeamento do estado ambiental desta região, enfatizando o uso e ocupação do solo com atenção especial às áreas de preservação permanentes relacionadas ao rio.

Assim, tanto nas ações de pesquisa (5,4\% dos projetos executados), como na extensão (14,6\% dos projetos executados), o percentual de ações focadas na sustentabilidade do rio São Francisco é considerado baixo, levando-se em consideração a importância que este recurso hídrico tem para a comunidade que vive às suas margens, conforme explicita esta pesquisa.

Da mesma forma, os discentes em estudo foram questionados a respeito de terem participado de projetos e outras ações educativas voltados para a temática em questão durante os 4 anos em que estiveram em formação pelo IFAL. A análise também avaliou esta participação usando como variável os cursos dos discentes, visando verificar se o quantitativo de participação dos alunos do curso voltados para as questões ambientais é mais significativo. (Figura 5): 


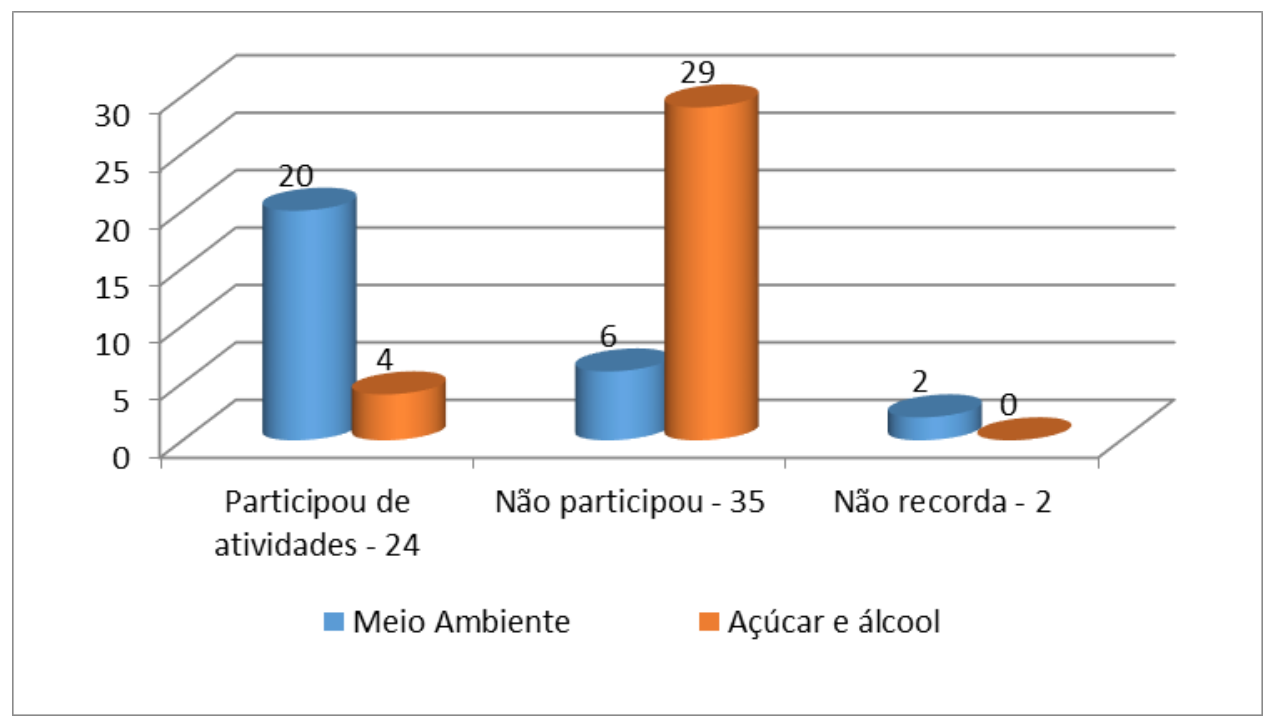

Figura 5: Gráfico comparativo da participação dos discentes em ações educativas voltadas para a conservação do rio São Francisco.

Fonte: Elaborado para esta pesquisa, 2017.

Dentre os 59 discentes entrevistados, 24 (40,7\%) participaram de atividades que promoviam a sustentabilidade do rio São Francisco, 35 (59,3\%) afirmam não terem participado de atividades voltadas para esta temática e 2 $(3,4 \%)$ entrevistados dizem não recordar.

Além disso, é possível verificar uma participação mais significativa dos alunos do curso de Meio Ambiente. A Figura 5 também evidencia um quantitativo elevado de alunos que não se envolveram em atividades em prol do rio no curso de Açúcar e Álcool.

\section{Demais ações promovidas pelos campi Penedo e Piranhas com foco na conservação do rio São Francisco}

Além dos projetos de pesquisa e extensão, algumas atividades são voltadas para conservação do rio São Francisco dentre as ações realizadas pelo campus Penedo. Além de ter entre os cursos ofertados o de técnico em Meio Ambiente, são desenvolvidos dois eventos que fazem parte do calendário anual: a Semana da Água e a Semana de Meio Ambiente, em parcerias com órgãos afins como Instituto do Meio Ambiente (IMA), ANA, Serviço Autônomo de Água e Esgoto de Penedo (SAAE), Universidade Federal de Alagoas (UFAL), Companhia de Desenvolvimento dos Vales do São Francisco e do Parnaíba (CODEVASF), prefeitura municipal, dentre outros, que estão voltados para as questões que envolvem o rio São Francisco.

Nestes eventos, que ocorrem respectivamente nos meses de março e junho, são desenvolvidas diversas atividades como palestras, minicursos, visitas ao rio no barco escola do IMA, peixamento, entre outras. Estas 
atividades são divulgadas pela sociedade por meio de redes sociais e mídia regional e abertas à comunidade. Além destes eventos já inseridos no calendário do campus, a Instituição promove a CIENITEC, semana tecnológica que também ocorre anualmente e que realiza minicursos e palestras que contemplam a sustentabilidade do rio São Francisco, além de workshops e outros eventos realizados com as instituições parceiras supracitadas.

\section{c) Percepção da comunidade escolar a respeito das ações educativas do IFAL para a sustentabilidade do rio São Francisco}

Como o objetivo desta pesquisa é analisar as ações educativas do IFAL e se estas promovem a sensibilização da comunidade escolar para a conservação do rio São Francisco, foi questionado se as ações anteriormente descritas haviam despertado a sensibilização de cada um para uma mudança de atitude em relação ao rio São Francisco.

Para 0 grupo entrevistado, os resultados quantitativos foram classificados em 3 categorias: dos 59 entrevistados, 24 (40,7\%) afirmam que as ações de cunho sustentável para o rio São Francisco despertaram a sensibilização destes indivíduos, classificando-as como ações transformadoras a ponto de promover a mudança de atitude em prol da conservação deste patrimônio natural. Dos entrevistados, $33(56,0 \%)$ relatam que não participaram de nenhuma atividade que contemplasse esta temática nos 4 anos que estiveram em formação pela instituição. Apenas 2 entrevistados $(3,4 \%)$ afirmaram que a sensibilização promovida não permitiu mudança de atitude em relação ao rio. Na Figura 6 a seguir, é possível observar um comparativo de como os cursos técnicos integrados do campus percebem as ações do IFAL:

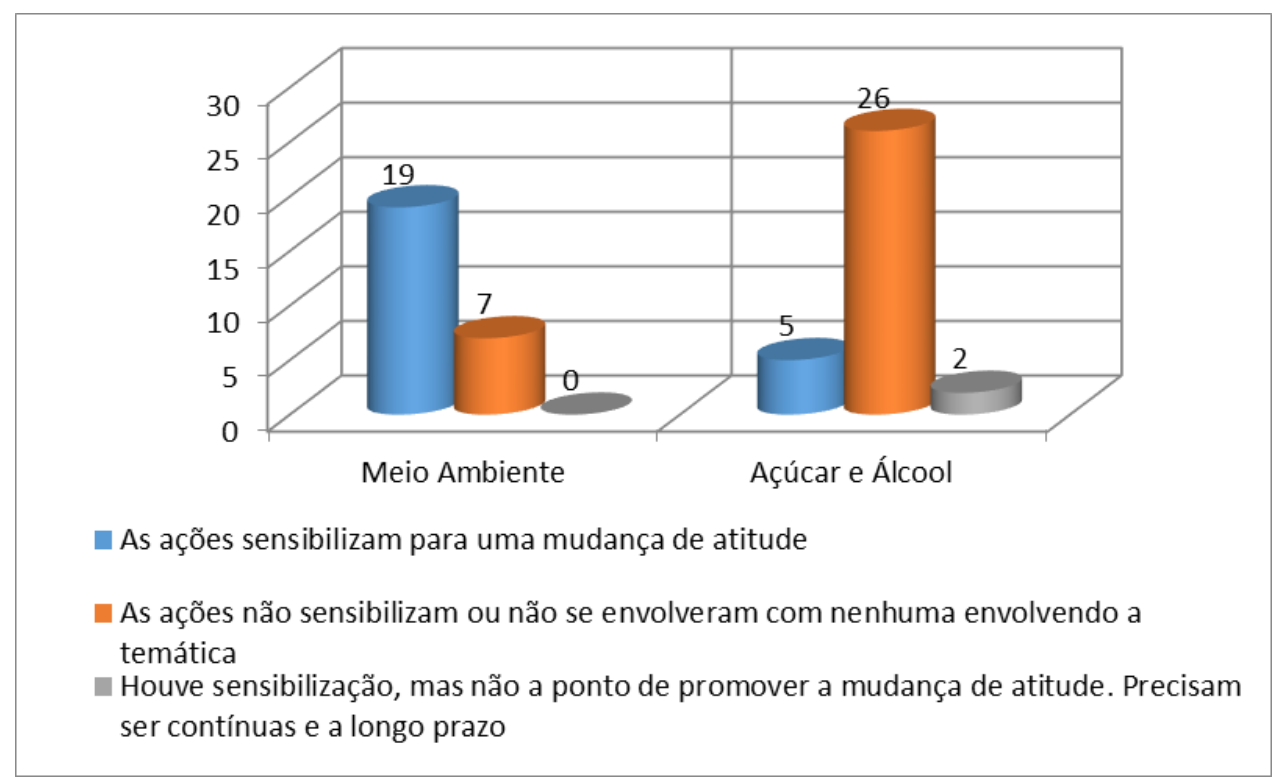

Figura 6: Gráfico comparativo entre discentes a respeito da sensibilização promovida pelas ações educativas do IFAL para a conservação do rio São Francisco.

Fonte: Elaborado para esta pesquisa, 2017. 


\section{Considerações Finais}

A partir dos resultados desta pesquisa, observou-se que $96,3 \%$ da comunidade escolar do campus ribeirinho do IFAL da cidade de Penedo (AL), situado na margem alagoana do Baixo São Francisco percebe a importância que o rio tem para o surgimento desta cidade, contemplando o viés histórico assim como o do desenvolvimento econômico, uma vez que de suas águas é garantido o abastecimento da população em suas necessidades primárias, no fomento à agricultura, à pecuária e à indústria. É notável ainda o papel do rio para o turismo, uma vez que ele se apresenta como principal atrativo para os que visitam as cidades que o margeiam, enriquecendo o comércio local e fortalecendo a rede hoteleira e de restaurantes. Destaca-se também a importância do Rio São Francisco para o transporte fluvial, para a geração de energia elétrica e como fonte de renda para os pescadores e piscicultores que dele retiram o sustento para suas famílias.

Da mesma forma, é necessário reconhecer que o desenvolvimento oriundo da exploração do rio trouxe impactos negativos que estão sendo evidenciados pela modificação da mata ciliar; a baixa da vazão, que promove 0 surgimento de bancos de areia e evidencia o fenômeno do assoreamento; o surgimento em larga escala de espécies bioindicadoras as quais alertam para a modificação dos aspectos físico-químicos da água provocados pelo lançamento de efluentes sem tratamento e outros poluentes, bem como a redução das espécies aquáticas que vivem no rio.

Como alternativa para reversão do atual quadro, $100 \%$ da comunidade escolar entrevistada aponta e percebe a educação como uma das principais ferramentas para a adoção de práticas sustentáveis para o manejo dos recursos do rio, uma vez que não vislumbra a possibilidade da não exploração destes recursos, pois deles dependem a economia e subsistência local. Assim, esta pesquisa ressalta que a educação da população ribeirinha é importante aliada para a conservação do principal recurso natural local aqui é apontado: o rio São Francisco.

Para tal, o IFAL, em seu papel de formar profissionais técnicos e cidadãos desenvolve ações de cunho educativo no intento de promover a sensibilização da comunidade escolar e local para a atenção em relação a recurso natural reconhecido pela própria comunidade como de vital importância para a subsistência do povoamento onde está instalado o campus pesquisado. Além dos projetos de extensão e pesquisa, o IFAL promove outras ações, tais como semana de fomento a ciência e tecnologia e campanhas em que a educação para a sustentabilidade é difundida para as comunidades locais.

Mesmo assim, tanto nas ações de pesquisa, como na extensão, o percentual de ações focadas na sustentabilidade do rio São Francisco é considerado baixo, levando-se em consideração a importância que este recurso hídrico tem para a comunidade que vive às suas margens, conforme explicita esta pesquisa. Tal informação é também refletida no percentual de discentes que se envolveram em atividades dentro desta temática promovidas

revista brasileira educação ambiental 
pelo campus, dado que $59,3 \%$ dos estudantes afirmam não terem participado de atividades voltadas para as práticas sustentáveis.

De toda forma, é possível verificar uma participação mais significativa dos alunos do curso de Meio Ambiente, contrastando com o quantitativo elevado de alunos que não se envolveram em atividades em prol do rio no curso de Açúcar e Álcool.

Assim, concluiu-se que os discentes do curso técnico integrado do campus Penedo, independente da área de formação, percebem que o rio São Francisco é o principal recurso natural da cidade, promotor do desenvolvimento socioeconômico local e que agoniza frente à evidente degradação ambiental. Reconhecem ainda a educação ambiental como importante ferramenta para a conservação do rio e que as ações educativas promovidas pelo campus ribeirinho de Penedo, sejam elas de pesquisa ou extensão, ou por meio de campanhas e similares, são incipientes no intento de sensibilizar a comunidade escolar quanto à conservação do rio São Francisco, e, por conseguinte, para a promoção de mudança de atitude dos indivíduos que com ele mantém relações de interdependência.

Para tanto, faz-se necessária a adoção de novas metodologias didáticas ou readequação das metodologias já utilizadas, uma vez que ações educativas transformadoras precisam transpor os limites das dependências do IFAL, fazendo com que a comunidade local, motivada pelo papel de multiplicador do conhecimento da instituição, mediante ações extensionistas, seja conscientizada e sensibilizada contribuindo de forma ativa e eficaz para conservação do rio São Francisco.

\section{Referências}

ABILIO, F. J. P., SATO, M. Educação Ambiental: do currículo da Educação Básica às vivências educativas no contexto do semiárido paraibano. João Pessoa: Editora Universitária da UFPB, 492 p., 2012.

AGUIAR NETTO, A. de O.; LUCAS, A. A. T.; SANTOS, A. G. C,; ALMEIDA, C. A. $P$ de. Água e ambiente no Baixo São Francisco Sergipano. In: LUCAS, A. A. T.; AGUIAR NETTO, A de O. (org.) Águas do São Francisco. São Cristóvão: Editora UFS, 2011, $312 \mathrm{p}$.

AGUIAR NETTO, A. de O.; SANTOS, T. I. S,; SANTOS, J. A.; SANTOS, R. R. da S.; NUNES, F. M. de O. Águas do São Francisco. In: AGUIAR NETTO, A de O.; SANTANA, N. R. F. (org.) Contexto Socioambiental das Águas do São Francisco. São Cristóvão: Editora UFS, 2015, 342 p.

ANA. Comitê de bacia hidrográfica: o que é e o que faz. Cadernos de capacitação em recursos hídricos; v. 1. Brasília: SAG, 2011. 64 p.

ANA. Região Hidrográfica do São Francisco. Disponível em: $<$ http://www2.ana.gov.br/Paginas/portais/bacias/SaoFrancisco.aspx>. Acesso em: 14 nov. 2016. 
ANTUNES, D. D. Uma didática interdisciplinar para uma efetiva ação educativa. Revista Educação por escrito - PUCRS, v. 1, n. 1, jun. 2010.

BRASIL. MINISTERIO DA EDUCAÇÃO. Parâmetros curriculares nacionais PCNs. Disponível em: <http://portal.mec.gov.br/seb/arquivos/pdf/blegais.pdf>. Acesso em: 10 dez. 2016.

BRASIL. MINISTERIO DA EDUCAÇÃO. Diretrizes curriculares nacionais para a educação ambiental. Resolução n 2, 15 de junho de 2012.

BRASIL. Histórico. Disponível em: <http://redefederal.mec.gov.br/historico>. Acesso em: 02 jun. 2017.

BRASIL. Expansão da Rede Federal. Disponível em: $<$ http://redefederal.mec.gov.br/expansao-da-rede-federal>. Acesso em: 02 jun. 2017.

CARVALHO, I. C. de M., Educação Ambiental: A formação do sujeito ecológico. São Paulo: Cortez, 2008.

CASAL. Companhia de Saneamento de Alagoas. Principais adutoras. Disponível em < http://casal.al.gov.br/areas-de atuacao/attachment/principais adutoras/>. Acesso em: 13 nov. 2016.

CBHSF. COMITÊ DA BACIA HIDROGRÁFICA DO RIO SÃO FRANCISCO. A descoberta do Rio São Francisco. Disponível em: $<$ http://cbhsaofrancisco.org.br/a-descoberta-do-rio-sao-francisco//>. Acesso em: 20 jul. 2016.

CBHSF. COMITÊ DA BACIA HIDROGRÁFICA DO RIO SÃO FRANCISCO. Câmara Consultiva Regional - CCR Baixo São Francisco. Disponível em: $<$ http://cbhsaofrancisco.org.br/ccrs/baixo-sao-francisco/>. Acesso em: 20 jul. 2016.

CBHSF. COMITÊ DA BACIA HIDROGRÁFICA DO RIO SÃO FRANCISCO. A Bacia. Disponível em: <http://cbhsaofrancisco.org.br/a-bacia/>. Acesso em: 20 jul. 2016.

CBHSF. COMITÊ DA BACIA HIDROGRÁFICA DO RIO SÃO FRANCISCO. Vazão será reduzida no início de janeiro no São Francisco. Disponível em: $<$ http://cbhsaofrancisco.org.br/vazao-sera-reduzida-no-inicio-de-janeiro-no-saofrancisco-2/ >. Acesso em: 26 dez. 2016.

CEMIG. Companhia Energética de Minas Gerais. Bacia do Rio São Francisco. Disponível em: <http://www.cemig.com.br/pt-br/A Cemig e o Futuro/sustentabilidade/nossos programas/ambientais/peixe vivo/Paginas/rio sao francisco.aspx>. Acesso em: 27 dez. 2016.

CHAGAS, R. M. Modelagem hidrodinâmica no Baixo São Francisco e análise da quantidade e da qualidade de água para irrigação. 2009. 136 p. Dissertação (Mestrado em Agroecossistemas) - Universidade Federal de Sergipe. São Cristóvão/SE: UFS, 2009. 
CHESF. Companhia Hidro Elétrica do São Francisco. Demonstrações Financeiras 2015. Disponível em: <https://www.chesf.gov.br/relainvest /Documents/DF\%20DEZ2015\%20CHESF PORTAL.pdf>. Acesso em $20 \mathrm{dez}$. 2016.

CHESF. Companhia Hidro Elétrica do São Francisco. Descrição de aproveitamento de Xingó. Disponível em: <https://www.chesf.gov.br/ SistemaChesf/Pages/SistemaGeracao/Xingo.aspx>. Acesso em: 20 dez. 2017.

CHESF. Companhia Hidro Elétrica do São Francisco. Fatos Históricos: Fatos \& Marcos. Disponível em: <https://www.chesf.gov.br/Comunicacao/Pages /Fatos\%20Hist\%C3\%B3ricos/FatosMarcos.aspx>. Acesso em 20 jan. 2017.

CODEVASF. COMPANHIA DE DESENVOLVIMENTO DOS VALES SÃO FRANCISCO E PARNAÍBA. Mapeamento temático de uso da terra no Baixo São Francisco. Brasília (DF), 2002.2 Disponível em: $<$ http://cbhsaofrancisco.org.br/?wpfb dl=1611>. Acesso em: 13 jul. 2016.

COIMBRA, J. de A. A. O outro lado do meio ambiente. São Paulo: Milenium, 2002.

DESO. COMPANHIA DE SANEAMENTO DE SERGIPE. Deso comemora os 515 anos do Rio São Francisco e destaca ações de preservação e conservação do manancial. Disponível em <http://www.desose.com.br/v2/index.php/deso-imprensa/noticias/item/1203-deso-comemora-os-

515-anos-do-rio-sao-francisco-e-destaca-acoes-de-preservacao-econservacao-do-manancial/1203-deso-comemora-os-515-anos-do-rio-saofrancisco-e-destaca-acoes-de-preservacao-e-conservacao-do-manancial>. Acesso em: 12 out. 2016.

DIAS, G. F. Educação Ambiental- Princípios e práticas. 8. Ed. São Paulo: Gaia, 2003.

FONTES, L. C. da S. O rio São Francisco após as grandes barragens: Mudanças recentes no regime hidrosedimentológico e na dinâmica fluvial no baixo curso. In: LUCAS, A. A. T.; AGUIAR NETTO, A de O. (org.) Águas do São Francisco. São Cristóvão: Editora UFS, 2011, 312 p.

FREIRE. P. Pedagogia da autonomia: saberes necessários para a prática educativa. 46 ed., Rio de Janeiro: Paz e Terra, 2013.

GIL, A. C. Métodos e técnicas de pesquisa social. 6. Ed. - 5. Reimpr. - São Paulo: Atlas, 2012, p. 200.

HOLANDA, F.R.; GOMES, L.G.N.; ROCHA, I. P.; SANTOS, T.T.; ARAÚJO FILHO, R.N., VIEIRA, T.R.S.; MESQUITA, J.B. Crescimento inicial de espécies florestais na recomposição da mata ciliar em taludes submetidos à técnica da bioengenharia de solos. Ciência Florestal, 20 (1), 157-166, 2010.

IFAL. Instituto Federal de Alagoas. Plano de Desenvolvimento Institucional PDI 2014 - 2018. Disponível em: <http://www.desenvolvimento.ifal.edu.br/ portal/ifal/reitoria/desenvolvimento-institucional>. Acesso em: 26 dez 2016. 
LEFÈVRE, F.; LEFÈVRE, A. M. C. Pesquisa de Representação Social. Brasília: Liberlivro; 2010.

MACHADO JUNIOR, M. C. Os impactos sociais e ambientais das grandes usinas hidrelétricas. $2010 . \quad$ Disponível em: $<$ http://www.webartigos.com/artigos/os-impactos-ambientais-e-sociais-dasgrandes-usinas-hidreletricas/32832/>. Acesso em: 12 de jan. 2017.

MARTINS, A. de O, SOUZA, G. S. A educação sustentável do consumidor e os efeitos do consumo exacerbado no mundo capitalista. Marília: Jornal da Fundação UNIVEM, 2013. Disponível em: <http://www.univem.edu.br /jornal/materia.php?id=340>. Acesso em: 14 out 2016.

MATOS, E. L. de. O pacto das águas e suas relações socioambientais com o Baixo São Francisco. 2014. 153 f. Tese (Doutor em Desenvolvimento e Meio Ambiente) - Universidade Federal de Sergipe. São Cristóvão/SE: UFS, 2014.

MINAYO, M. C. de S. O desafio da pesquisa social. In: MINAYO, M. C. de S (org.) Pesquisa Social: teoria, método e criatividade. 32 $2^{\text {a }}$ ed., Petrópolis: Vozes, 2012.

MINAYO, M. C. de S. Trabalho de campo: contexto de observação, interação e descoberta. In: MINAYO, M. C. de S (org.) Pesquisa Social: teoria, método e criatividade. 32 ${ }^{\mathrm{a}}$ ed., Petrópolis: Vozes, 2012.

SEIFFERT, M. E. B. Gestão ambiental: instrumentos, esferas de ação e educação ambiental. - 2. ed. - São Paulo: Atlas, 2011.

THIOLLENT, M. Metodologia da pesquisa-ação. São Paulo: Cortez, 1986.

TRIVIÑOS, A. N. S. Introdução à pesquisa em ciências sociais: a pesquisa qualitativa em educação. 1. Ed. - 22 reimpr. - São Paulo: Atlas, 2013.

VIEIRA, R. H. S. F.; ROCHA, C. A. S.; MENEZES, F. G. R.; ARAGÃO, J. S.; RODRIGUES, D. P.; THEOPHILO, G. N. D.; REIS, E. M. F. Poluição da água do mar e da areia de três praias de Fortaleza, Ceará, Brasil. Arquivos de Ciências do Mar. 35:113-118. 2002. 